\title{
Growth, development and nutritional indices of tobacco caterpillar, Spodoptera litura (F) raised on bell pepper plants grown under elevated $\mathrm{CO}_{2}$ and temperature conditions
}

\author{
MEENA KUMARI ${ }^{*}$ and S.C. VERMA ${ }^{2}$ \\ ${ }^{1}$ Dept. of Environmental Science, ${ }^{2}$ Dept. of Entomology \\ Dr. Y.S. Parmar University of Horticulture and Forestry Nauni - Solan (H.P.), India \\ *Corresponding author : meena.sankhyan@gmail.com
}

\begin{abstract}
The experiment was conducted at experimental farm situated at $30^{\circ} 5^{\prime} \mathrm{N}$ latitude and about $77^{\circ} 11^{\prime} \mathrm{E}$ longitudes, an elevation of $1260 \mathrm{~m}$ above mean sea level of Department of Environmental Science, Dr YS Parmar University of Horticulture and Forestry Nauni, Solan, Himachal Pradesh during 2014 and 2015, to study the effect of elevated $\mathrm{CO}_{2}\left(e \mathrm{CO}_{2}\right)$ and elevated temperature $(e \mathrm{~T})$ on growth, development and nutritional indices of Spodopteralitura on bell pepper plant. Feeding trials with foliage feeding insect $S$. litura was conducted using foliage of bell pepper plants grown under four concentrations of $\mathrm{CO}_{2}$ and temperature, viz. three Open Top Chambers, $\left(\mathrm{T}_{1}\right.$ : OTC eCO $550 \pm 10 \mathrm{ppm} ; \mathrm{T}_{2}$ : OTC with elevated temperature $1^{\circ} \mathrm{C}$ higher and $e \mathrm{CO}_{2} 550 \pm 10 \mathrm{ppm} ; \mathrm{T}_{3}$ : OTC with ambient temperature and $\mathrm{CO}_{2}$ and $\mathrm{T}_{4}$ : natural ambient air and temperature in open. Biochemical analysis of foliage revealed that plants grown under elevated $\mathrm{CO}_{2}$ had lower nitrogen. The larvae fed on $\mathrm{eCO}_{2}$ as well as $\mathrm{eCO}_{2}$ and temperature foliage exhibited greater consumption compared to the larvae fed on foliage under ambient $\mathrm{CO}_{2}$. Larval duration also increased by two days. The $\mathrm{eCO}_{2}$ and $\mathrm{eCO}_{2}$ and temperature foliage was more digestible with higher values of approximate digestibility. The relative consumption rate increased whereas the efficiency parameters, viz. efficiency of conversion of ingested food (ECI), efficiency of conversion of digested food (ECD), and relative growth rate (RGR) decreased in $\mathrm{eCO}_{2}$ and $\mathrm{eCO}_{2}$ and temperature. The consumption and weight gain of the larvae were negatively and significantly influenced by leaf nitrogen.
\end{abstract}

Key words: Capsicum, e $\mathrm{CO}_{2}$, elevated temperature, open top chamber, nutritional indices

Climate change, especially rise in temperature and atmospheric carbon dioxide concentration, is a major concern today. The concentration of $\mathrm{CO}_{2}$ in the atmosphere may rise above 500 ppm by the next decade. Changes in climate are expected to have significant impacts on crop yields through temperature and carbon dioxide induced changes which in turn are likely to influence insect-plant interactions in several ways. The effects of climate change on insect pests can be both direct and indirect. Many plant species respond to enriched atmospheric $\mathrm{CO}_{2}$ by enhanced photosynthetic rates and increase in biomass as well as alterations in leaf quality factors. This might affect growth of leaf eating insects through altered consumption and digestibility. The tobacco caterpillar, Spodoptera litura Fabricius (Lepidoptera: Noctuidae) is polyphagous pest, damaging many economically important vegetables and ornamental plants and has a huge potential to invade new areas by adapting to wide range of ecological situations (Sharma and Brar, 2018). Temperature, which impacts the development time, longevity and fecundity of insects has a direct effect while elevated $\mathrm{CO}_{2}\left(e \mathrm{CO}_{2}\right)$ has an indirect host- mediated effect on growth and development of insect pests (Yadugiri, 2010). Because leaf nitrogen is considered essential for growth and reproduction of insects a reduction in nitrogen content of leaves grown under elevated $\mathrm{CO}_{2}$ may elicit strong responses by them. As a consequence of these tight ecological linkages, the interplay between plants and herbivorous insects in the tropics can be affected by the perturbations of climate change. The most predicted effects of climate change, i.e., increase in atmospheric temperature and $\mathrm{CO}_{2}$ concentration will have a significant effect on agriculture in general and on herbivore insect populations in particular. Temperature and $\mathrm{CO}_{2}$ (Rao et al., 2012) are known to alter the growth and development of S. litura. Increasing level of $\mathrm{CO}_{2}$ and temperature is affecting the growth, development and plant biochemistry of bell pepper in this region and hence influence insect-plant interactions which can cause drastic reductions in commercial yield and affect the livelihood of farmers. Among the damaging species, the tobacco armyworm, $S$. litura, is as a major pest, and can cause yield losses of $35-55 \%$. The tobacco caterpillar, S. litura larvae 
feed on the foliage and complete their life cycle. Larvae feed gregariously on leaves, causing severe defoliation, leaving midrib veins only. Response of herbivory to elevated $\mathrm{CO}_{2}$ is highly complex, and the interactions between legumes and insect-herbivores are unclear (Rao et al., 2012). The present study was aimed to elucidate the effect of $e \mathrm{CO}_{2}$ and temperature on leaf quality of bell pepper and the cumulative effect on various growth indices of S. litura fed with $e \mathrm{CO}_{2}$ grown bell pepper foliage.

\section{MATERIALS AND METHODS}

The present experiment was conducted at farm of Department of Environmental Science, Dr YS Parmar University of Horticulture and Forestry, Nauni, Solan India in the year 2014 and 2015. The Experimental farm is situated at $30^{\circ} 5^{\prime} \mathrm{N}$ latitude and about $77^{\circ} 11^{\prime} \mathrm{E}$ longitudes and at an elevation of $1260 \mathrm{~m}$ above mean sea level. Circular type open top chambers (OTC) of $4 \times 4 \mathrm{~m}^{2}$ dimension were used to raise the crop under elevated and ambient $\mathrm{CO}_{2}$ and temperature conditions. An automatic $\mathrm{CO}_{2}$ enrichment and temperature technology was developed by adapting software SCADA to automatically maintain the desired and accurate levels of $\mathrm{CO}_{2}$ and temperature around crop canopy inside OTCs. Carbon dioxide gas was supplied to the chambers and maintained at set levels using manifold gas regulators, pressure pipelines, solenoid valves, rotameters, sampler, pump, $\mathrm{CO}_{2}$ analyzer, PC linked Program Logic Control (PLC) and Supervisory Control and Data Acquisition (SCADA). The concentration of $\mathrm{CO}_{2}$ in the chamber was monitored by a non dispersive infrared (NDIR) gas analyser. There were four treatmentsi.e. $\mathrm{T}_{1}$ : elevated $\mathrm{CO}_{2}(550 \pm 10 \mathrm{ppm}), \mathrm{T}_{2}$ :elevated $\mathrm{CO}_{2}$ and temperature $\left(\mathrm{CO}_{2}: 550 \pm 10 \mathrm{ppm}\right.$, temperature: $1{ }^{\circ} \mathrm{C}$ elevated than $\mathrm{T}_{1}$ ), $\mathrm{T}_{3}$ : ambient temperature (reference) and $\mathrm{T}_{4}$ : natural air and temperature condition (control). The bell pepper crop was transplanted during crop growing seasons of the experiment by following recommended package of practices.

The growth, development as well as nutritional indices of $S$. litura $\mathrm{F}$. in bell pepper was studied under all the four conditions. The adults of S. litura F. was collected from field. The pure culture of $S$. litura $\mathrm{F}$. was maintained in the laboratory on bell pepper leaves. The freshly laid eggs were used for the experiment. After hatching of eggs larvae were placed on petri dishes with bell pepper leaves obtained from plants raised under different treatments. Each larva was provided with the leaves of plants grown in the same treatment throughout the life. Before placing the leaves in petri dishes a moistened filter paper was kept so that humidity was maintained to prevent desiccation (Hasan and Ansari 2011). The feeding of larvae was performed in four replications. Each replication consists of five larvae placed on single petri dish. The larvae were transferred to big transparent jar after four days to avoid congestion in petri dishes. Initially weight was measured for five larvae collectively and average value per larva was worked out. After fourth day onwards measurements were done independently. Before offering leaves to larvae the initial weight of larva as well as leaf were measured and then after 24 hours weight of remaining leaf, larval weight and faecal matter was recorded. The leaves from each treatment were provided to larvae till they undergo in pupation. Later on, pupal period and pupal weight was recorded.

\section{Chemical analysis of leaves}

For estimation of $\mathrm{N}, 0.5 \mathrm{~g}$ of plant material (leaf sample taken before flowering stage) was digested in concentrated $\mathrm{H}_{2} \mathrm{SO}_{4}$ in the presence of a digestion mixture. After digestion, the $\mathrm{N}$ was determined by micro-kjeldahl method. Leaf nitrogen content was measured by adopting the standard procedure given by Jackson (1973).

\section{Instruments/apparatus used}

1. Infrared Digestion system (or Digestion Chamber having a fame exhaust system, if gas burners are used).

2. Automatic distillation-cum-titration system or distillation system.

\section{Reagents}

1. $0.1 \mathrm{~N} \mathrm{H}_{2} \mathrm{SO}_{4}$ : Dilute suitable volume of cone. $\mathrm{H}_{2} \mathrm{SO}_{4}$ approximately $0.1 \mathrm{~N} \mathrm{H}_{2} \mathrm{SO}_{4}$ and standardize it against 0.1. $\mathrm{N} \mathrm{NaOH}$.

2. Boric acid (4\%) with mixed indicator: Prepared $4 \%$ aqueous solution of boric acid, added mixed indicator and adjust $\mathrm{pH}$ at 4.5 .

3. Digestion accelerator mixture: Mixed 20 parts of anhydrous $\mathrm{Na}_{2} \mathrm{SO}_{4}$ or $\mathrm{K}_{2} \mathrm{SO}_{4}$ with 1 part of $\mathrm{CuSO}_{4} \cdot 5 \mathrm{H}_{2} 0$ or commercially available tablets composed of $\mathrm{K}_{2} \mathrm{SO}_{4}$ and $\mathrm{CuSO}_{4} \cdot 5 \mathrm{H}_{2} 0$.

\section{Procedure adopted for digestion of sample on digestion block}

- Weigh the sample and wrap in filter paper and place 
in digestion tube. Added one tablet of the digestion accelerator or mixture and $6 \mathrm{~mL}$ of conc. $\mathrm{H}_{2} \mathrm{SO}_{4}$.

- Set the digestion system to attain a temperature of about $385^{\circ} \mathrm{C}$ and then attached the digestion tube to the heating unit as per the instructions given in the operation manual.

- $\quad$ Run the tap water with desired flow rate for safe disposal of fumes and allowed the digestion to continue till completion (no black or brown colour), which takes about 60 to 75 minutes.

- Switched-off the system and removed the rack of sample tubes along with the exhaust system from the heating unit. Do not stop water flow as the fumes continue coming for some more time.

- Set the distillation unit to perform various steps, viz. dilution, addition of alkali, steam generation, titration etc.

- Keep boric acid in conical flask and run the distillation for 150 seconds then titrated the distillate against $0.1 \mathrm{~N}$ $\mathrm{H}_{2} \mathrm{SO}_{4}$ until a purple color just starts appearing.

- Once the samples are digested, the subsequent titration can also be followed manually.

- Utmost care should be exercised during addition of $40 \%$ $\mathrm{NaOH}$, if done manually.

\section{Insect performance indices}

Data on larval weight (g), larval period (days), fecal matter (g), pupal period (days), pupal weight (g), adult longevity (days), fecundity (number of eggs/female) was recorded. Data regarding amount of food consumed, fecal matter produced and weight gained was utilized to work out the various nutritional indices, on fresh weight basis (by taking into consideration the fresh weight of food, fecal matter and the insect) relative growth rate (RGR, larval weight gain per day as a fraction of body weight), relative consumption rate (RCR, weight of leaf ingested per day as a fraction of larval body weight), efficiency of conversion of ingested food (ECI, larval weight gain per unit weight of leaf ingested expressed as \%), efficiency of conversion of digested food (ECD, larval weight gain per unit weight of leaf digested expressed as \%) and approximate digestibility ( $\mathrm{AD}$, ratio of weight of leaf digested and weight of leaf ingested expressed as per cent . A pair of adults was kept in one chamber and the number of eggs laid by the female during entire life was counted.

\section{RESULTS AND DISCUSSION}

\section{Biochemical analysis of leaf samples $\mid$}

Leaf nitrogen content was distinctly lower in $e \mathrm{CO}_{2}$ foliage (4.08\%) followed by $e \mathrm{CO}_{2}$ and $e \mathrm{~T}(4.39 \%), a \mathrm{CO}_{2}$ and temperature (5.16\%) and open condition (5.73\%) (Fig. $1)$.

\section{Growth performance of S. litura}

\section{Larval weight}

It is evident from Table 1 that $S$. litura larvae fed on foliage of bell pepper grown under $e \mathrm{CO}_{2}$ gained significantly maximum weight $(0.51 \mathrm{~g})$ while larval weight decreased under $e \mathrm{CO}_{2}$ and temperature $(0.44 \mathrm{~g})$ and $a \mathrm{CO}_{2}$ and temperature $(0.32 \mathrm{~g})$. S. litura larvae fed on foliage of natural condition gained minimum weight $(0.29 \mathrm{~g})$. Larval weight under $a \mathrm{CO}_{2}$ and temperature was statistically at par with natural condition and overall average weight of $0.39 \mathrm{~g} \pm 0.10$ (Stnd. Dev.). $S$. litura larvae gained maximum weight under $e \mathrm{CO}_{2}$ compared to $a \mathrm{CO}_{2}$ and temperature and natural condition which may be due to change in $\mathrm{C} / \mathrm{N}$ ratio. In present investigations, $S$. litura larvae fed on foliage of bell pepper plants grown under $e \mathrm{CO}_{2}$ gained maximum weight compared to $a \mathrm{CO}_{2}$ and temperature and natural condition which may be due to lower foliar nitrogen content under $e \mathrm{CO}_{2}$ which causes an increase in food consumption by S. litura in order to compensate their nutritional requirement and hence resulted increased larval weight as compared to $a \mathrm{CO}_{2}$ and temperature and natural condition. These results corroborate the findings of Rao et al. (2012) who reported that there was increased larval weight $(18 \%$ and $32 \%)$ of S. litura with higher fecal matter release under both $e \mathrm{CO}_{2}$ treatments over $a \mathrm{CO}_{2}$ and temperature.

\section{Larval period}

Larval period S. liturai ncreased with foliage of $e \mathrm{CO}_{2}$ (19.92 days) followed by $e \mathrm{CO}_{2}$ and temperature (18.76 days) and $a \mathrm{CO}_{2}$ and temperature (17.71 days). Minimum larval period was with foliage of natural condition (16.81 days). Overall average larval period was $18.30 \pm 1.34$ (days). Longer larval period was observed when larvae were fed on foliage of $e \mathrm{CO}_{2}$ which may be attributed to lower quality of foliage which resulted longer larval period and slower growth of larva. Foliage of bell pepper plants grown under $e \mathrm{CO}_{2}$ concentrations contained lower leaf nitrogen due to which larvae consumed more food. So larvae got less nutrition by feeding on more bulk of food in order to compensate their nutritional demand and hence resulted longer larval period. 


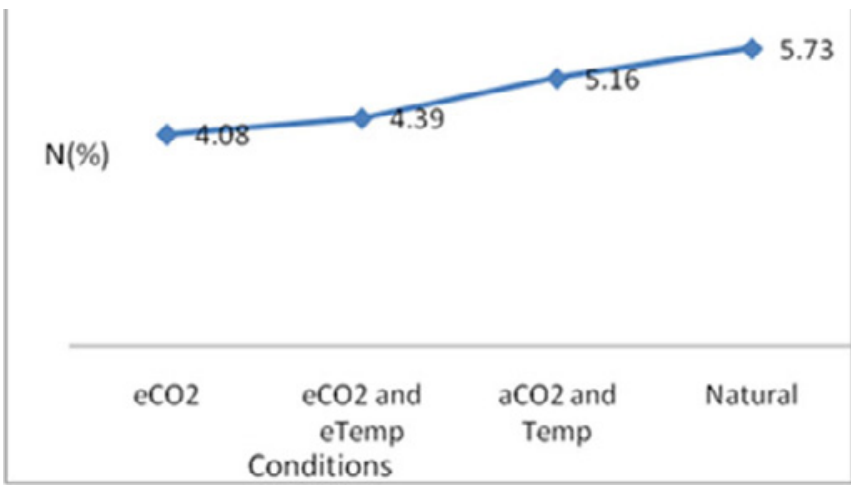

Fig. 1 : Nitrogen content (\%) in leaf of bell pepper

These findings are in agreement with the findings of Rao et al. (2012) who stated that growth and development of the tobacco caterpillar, S. litura (F.) reared on peanut (Arachis hypogea L.) foliage grown under $e \mathrm{CO}_{2}$ leads to longer larval duration and increased consumption of peanut foliage by $S$. litura larvae under $e \mathrm{CO}_{2}$ compared with $a \mathrm{CO}_{2}$. In the present findings, the larval period was less undere $\mathrm{CO}_{2}$ and elevated temperature in comparison to elevated $\mathrm{CO}_{2}$ which may be due to increase in temperature which interacted negatively against $e \mathrm{CO}_{2}$ and caused increased nitrogen content and ultimately resulted reduced the larval duration.

\section{Fecal matter}

In all conditions average fecal matter $0.37 \pm 0.05(\mathrm{~g})$ was produced by larvae. Whereas when $S$. litura larvae fed on foliage of $e \mathrm{CO}_{2}(0.42 \mathrm{~g})$ produced as much fecal matter as $e \mathrm{CO}_{2}$ and temperature $(0.40 \mathrm{~g})$ and differed statistically from $a \mathrm{CO}_{2}$ and temperature $(0.35 \mathrm{~g})$ and natural condition $(0.31 \mathrm{~g})$. Lower foliar nitrogen content under $e \mathrm{CO}_{2}$ caused increase in food consumption by $S$. litura in order to compensate their nutritional requirement and hence released more fecal matter as compared to $a \mathrm{CO}_{2}$ and temperature and natural condition. The results are in consonance with findings of Rao et al. (2012) who have also reported that higher fecal matter release was observed under $e \mathrm{CO}_{2}$ over $a \mathrm{CO}_{2}$ and temperature.

\section{Pupal period}

Significantly longest pupal period was recorded with $e \mathrm{CO}_{2}$ (11.84 days) followed by $e \mathrm{CO}_{2}$ and temperature (10.87 days), $a \mathrm{CO}_{2}$ and temperature (9.34 days) while minimum pupal period was with natural condition (8.63 days). $a \mathrm{CO}_{2}$ and temperature was statistically at par with pupal period under natural condition. An average of $10.17 \pm 1.45$ pupal period was recorded in all conditions. In the present study, longest pupal period was recorded under $e \mathrm{CO}_{2}$ which may be due to enhancement of overall growth period of insect under the influence of nutritionally poor food which slower the development at each stage of insect. The present results corroborate with the findings of Robinson et al. (2012) who reported that herbivores exposed to elevated concentrations of $\mathrm{CO}_{2}$ had longer pupal period compared to ambient condition of $\mathrm{CO}_{2}$.

\section{Pupal weight}

Over all $0.29 \pm 0.02$ (g) pupal weight was recorded whereas Tobacco caterpillar, $S$. litura pupae gained significantly higher pupal weight under natural condition $(0.32 \mathrm{~g})$ which was statistically at par with $a \mathrm{CO}_{2}$ and temperature $(0.31 \mathrm{~g})$ and differed statistically from $e \mathrm{CO}_{2}$ $(0.28 \mathrm{~g})$ and $e \mathrm{CO}_{2}$ and temperature. Lowest pupal weight was recorded with $e \mathrm{CO}_{2}$ and temperature $(0.27 \mathrm{~g})$.In the present study, $e \mathrm{CO}_{2}$ and temperature caused lowest pupal weight which may be due to reduction in food quality that might have caused the higher feeding by larvae and digestion was less which caused decreased pupal weight. Because nitrogen is the chief constituent of proteins so the plants grown under $e \mathrm{CO}_{2}$ have lower in protein content, this resulted higher feeding by larvae but less digestion and caused decreased pupal weight. These results are in accordance with the findings of Rao et al. (2012) who reported that an increase in developmental time with decreased pupal weights was observed when larvae of $S$. litura were reared from hatching to pupation on $e \mathrm{CO}_{2}$ grown peanut crop. In the present findings, it has also been observed that elevated temperature in combination with $e \mathrm{CO}_{2}$ caused decreased pupal weight as compared to $e \mathrm{CO}_{2}$ only and these results are in consonance with findings of Baeand Park (1999) who also reported that increase in temperature cause decreased in pupal weight by 3-13 per cent.

\section{Fecundity}

Maximum egg laying was observed under natural condition (886.19 eggs/female) followed by $a \mathrm{CO}_{2}$ and temperature (799.71 eggs/female), $\mathrm{CCO}_{2}$ (756.23 eggs/ female) and $e \mathrm{CO}_{2}$ and temperature (733.54 eggs/ female). Elevated $\mathrm{CO}_{2}$ and temperature was statistically at par with $e \mathrm{CO}_{2}$. On an average 793.91 $\pm 67.36 \mathrm{eggs} /$ female fecundity was recorded in all conditions.In present investigations, elevated $\mathrm{CO}_{2}$ and temperature caused lower pupal weight which might have affected lower fecundity. Similar to present findings Bae and Park (1999) reported that lower pupal weight affected the fecundity.

\section{Relative growth rate (RGR)}

Higher growth rate (119.68) was with natural 
Table 1: Effect of elevated $\mathrm{CO}_{2}$ and temperature on growth, development of $S$.litura on bell pepper (pooled data)

\begin{tabular}{llllll}
\hline Treatment & $\begin{array}{l}\text { Larval } \\
\text { weight } \\
(\mathrm{g})\end{array}$ & $\begin{array}{l}\text { Larval period } \\
\text { (days) }\end{array}$ & $\begin{array}{l}\text { Fecal matter } \\
(\mathrm{g})\end{array}$ & $\begin{array}{l}\text { Pupal period } \\
(\text { days })\end{array}$ & $\begin{array}{l}\text { Pupal weight } \\
(\mathrm{g})\end{array}$ \\
\hline $\mathrm{T}_{1}:$ Elevated $\mathrm{CO}_{2}(550 \pm 10 \mathrm{PPM})$ & 0.51 & 19.92 & 0.42 & 11.84 & 0.28 \\
$\mathrm{~T}_{2}:$ Elevated $\mathrm{CO}_{2}$ and elevated temp $(550 \pm 10$ & 0.44 & 18.76 & 0.40 & 10.87 & 0.27 \\
$\quad$ PPM \& $\left.1{ }^{\circ} \mathrm{C}\right)$ & 0.32 & 17.71 & 0.35 & 9.34 & 0.31 \\
$\mathrm{~T}_{3}:$ Ambient $\mathrm{CO}_{2}$ and temperature & 0.29 & 16.81 & 0.31 & 8.63 & 0.32 \\
$\mathrm{~T}_{4}:$ Natural condition (control) & $0.39 \pm 0.10$ & $18.30 \pm 1.34$ & $0.37 \pm 0.05$ & $10.17 \pm 1.45$ & $0.29 \pm 0.02$ \\
Mean $\pm \mathrm{SD}$ & 0.06 & 0.81 & 0.05 & 1.00 & 0.01 \\
\hline LSD (p $=0.05)$ & & & & & \\
\hline
\end{tabular}

Table 2: Effect of elevated $\mathrm{CO}_{2}$ and temperature on various nutritional indices of S.litura insect of bell pepper (pooled data)

\begin{tabular}{|c|c|c|c|c|c|c|}
\hline Treatment & $\begin{array}{l}\text { Fecundity } \\
\text { (No of eggs/ } \\
\text { female) }\end{array}$ & RGR & $\begin{array}{l}\text { ECI } \\
(\%)\end{array}$ & RCR & $\begin{array}{l}\mathrm{AD} \\
(\%)\end{array}$ & $\begin{array}{l}\text { ECD } \\
(\%)\end{array}$ \\
\hline $\mathrm{T}_{1}$ : Elevated $\mathrm{CO}_{2}(550 \pm 10 \mathrm{PPM})$ & 756.23 & 92.93 & 36.14 & 64.86 & 84.24 & 43.23 \\
\hline $\begin{array}{l}\mathrm{T}_{2}: \text { Elevated } \mathrm{CO}_{2} \text { and elevated temp } \\
\left(550 \pm 10 \text { PPM \& } 1^{\circ} \mathrm{C}\right)\end{array}$ & 733.54 & 84.07 & 41.33 & 52.05 & 74.62 & 60.57 \\
\hline $\mathrm{T}_{3}:$ Ambient $\mathrm{CO}_{2}$ and temperature & 799.71 & 103.01 & 36.41 & 43.50 & 74.20 & 49.78 \\
\hline $\mathrm{T}_{4}:$ Natural condition (control) & 886.19 & 119.68 & 47.79 & 31.63 & 70.92 & 68.42 \\
\hline Mean \pm SD & $793.91 \pm 67.36$ & $99.92 \pm 15.27$ & $40.42 \pm 5.46$ & $48.01 \pm 14.01$ & $75.99 \pm 5.74$ & $55.50 \pm 11.19$ \\
\hline LSD $\quad(p=0.05)$ & 51.74 & 26.07 & 10.63 & 12.61 & 11.43 & 21.34 \\
\hline
\end{tabular}

condition was statistically at par with $a \mathrm{CO}_{2}$ and temperature (103.01) and differed statistically from $e \mathrm{CO}_{2}$ (92.93) and $e \mathrm{CO}_{2}$ and temperature (84.07). Minimum relative growth rate was recorded with $e \mathrm{CO}_{2}$ and temperature. Average of 99.92 \pm 15.27 RGR was found in all conditions. In this study, relative growth rate of $S$. litura reduced when larvae fed on foliage of bell pepper plants grown under $e \mathrm{CO}_{2}$ as well as $e \mathrm{CO}_{2}$ and temperature which may be due to less nutrition of foliage under $e \mathrm{CO}_{2}$ and temperature. The present results are in accordance with the findings of Hatten schwiler and Schafellner (2004) who reported that relative growth rates of gypsy moth (Lyman triadispar) be reduced by 30 per cent when larvae fed on leaves of Quercus petraea exposed to high $\mathrm{CO}_{2}$.

\section{Relative consumption rate ( $R C R$ )}

Relative consumption rate of $S$. litura larvae was at an average of $40.42 \pm 5.46$ found in all conditions whereas higher under elevated $\mathrm{CO}_{2}$ (64.86) which was statistically at par with elevated $\mathrm{CO}_{2}$ and temperature (52.05) and differed statistically from ambient $\mathrm{CO}_{2}$ and temperature (43.50) and natural condition (31.63). In the present investigations, higher relative consumption rate was observed under $e \mathrm{CO}_{2}$ which probably may be due to changes in foliar chemical constituents which have caused more consumption of leaves by $S$. litura. The present results were in agreement with the findings of Coviella et al. (2000) who observed that when insects fed on $e \mathrm{CO}_{2}$ grown plants showed increase in their individual consumption due to the poor food quality of these plants. Rao et al. (2012) also reported that relative consumption rate was significantly higher for $S$. litura larva fed on plants grown at 550 and $700 \mathrm{ppm}$ than for larvae fed on plants grown at ambient treatment.

\section{Efficiency of conversion of ingested food}

Efficiency of conversion of ingested food was maximum $(47.79 \%)$ with natural condition followed by $e \mathrm{CO}_{2}$ and temperature (41.33\%) and $a \mathrm{CO}_{2}$ and temperature (36.41\%) and least with $e \mathrm{CO}_{2}$ (36.14\%). An average of $48.01 \% \pm 14.01$ was recorded in all conditions. In the present findings it has been observed that $S$. litura increased foliage consumption when fed on nitrogen-poor foliage which caused decreased efficiency of conversion of food into body mass. Similarly, Rao et al. (2012) reported that efficiency of conversion of ingested food by S. litura decreased in first and second generations under $e \mathrm{CO}_{2}$ compared to ambient condition. 


\section{Approximate digestibility $(A D)$}

Approximate digestibility was maximum (84.24\%) with $e \mathrm{CO}_{2}$ which was statistically at par with $e \mathrm{CO}_{2}$ and temperature (74.62\%), $a \mathrm{CO}_{2}$ and temperature $(74.20 \%)$. Least digestibility was with natural condition (70.92\%). An average $75.99 \% \pm 5.74 \mathrm{AD}$ was recorded. Higher approximate digestibility was recorded under $e \mathrm{CO}_{2}$ which may be due to lower nitrogen content in the foliage grown under $e \mathrm{CO}_{2}$. Higher approximate digestibility (AD) under elevated $\mathrm{CO}_{2}$ may be attributed to accumulation of starch content and lower $\mathrm{N}$ content (Wang et al., 2008). The present findings indicated that the digestive efficiency (AD) increased and conversion efficiency (ECD) decreased for larvae fed on $\mathrm{eCO}_{2}$ grown foliage.

\section{Efficiency of conversion of digested food (ECD)}

Maximum efficiency of conversion of digested food $(68.42 \%)$ was with natural condition which was statistically at par with $e \mathrm{CO}_{2}$ and elevated temperature (60.57\%) and $a \mathrm{CO}_{2}$ and temperature $(49.78 \%)$. Least efficiency of conversion of digested food was recorded with $e \mathrm{CO}_{2}$ (43.23\%) whereas overall average was $55.50 \% \pm 11.19$. In the present findings, it has been found that efficiency of conversion of digested food by $S$. litura was low under $e \mathrm{CO}_{2}$ which may be due to low nutritional quality of food grown under $e \mathrm{CO}_{2}$. Similar to present findings Rao et al. (2012) reported significantly lower efficiency of conversion of digested food (by 35\% in 550 ppm and $32 \%$ in $700 \mathrm{ppm}$ ) of for $S$. litura larvae as compared to ambient condition. The present study is in agreement with the findings of Lawler et al. (1997) that herbivores responded to altered primary and secondary metabolism of plant under elevated $\mathrm{CO}_{2}$ by increasing food consumption to counter balance for the lowered nutritional quality by decreasing food conversion efficiency.

\section{CONCLUSION}

Biochemical analysis of foliage revealed that plants grown under elevated $\mathrm{CO}_{2}$ had lower nitrogen. The larvae fed on $e \mathrm{CO}_{2}$ as well as $e \mathrm{CO}_{2}$ and temperature foliage exhibited greater consumption compared to the larvae fed on foliage under ambient $\mathrm{CO}_{2}$. Larval duration also increased by two days. The $e \mathrm{CO}_{2}$ and $e \mathrm{CO}_{2}$ and temperature foliage was more digestible with higher values of approximate digestibility. The relative consumption rate increased whereas the efficiency parameters, viz. efficiency of conversion of ingested food (ECI), efficiency of conversion of digested food (ECD), and relative growth rate (RGR) decreased in $e \mathrm{CO}_{2}$ and $e \mathrm{CO}_{2}$ and temperature. The growth and development of leaf eating insects certainly to be affected and changed through altered consumption and digestibility under ensuing climatic variability.

\section{REFERENCES}

Bae, S.D. and Park, K.B. (1999). Effects of temperature and food source on pupal development, adult longevity and oviposition of the tobacco cutworm, Spodoptera litura Fabricius. Korean J. Appl. Entomol., 38: 2328.

Coviella, C.E., Stipanovic, R.D. and Trumble, J.T. (2000). Plant allocation to defensive compounds: interactions between elevated $\mathrm{CO}_{2}$ and nitrogen in transgenic cotton plants. J. Exp. Bot., 53(367): 323- 331.

Hasan, F. and Ansari, M. S. (2011). Population growth of Pieris brassicae (L.) (Lepidoptera: Pieridae) on different cole crops under laboratory conditions. $J$. Pest Sci., 84:179- 186.

Hatten schwiler, S. and Schafellner, C. (2004). Gypsy moth feeding in the canopy of a $\mathrm{CO}_{2}$ - enriched mature forest. Glob Chang Biol., 10: 1899-1908.

Jackson, M.L. (1973). Soil chemical analysis. Prentice Hall of India Pvt. Ltd., New Delhi, p. 38-56.

Lawler, I.R., Foley, W.J., Woodrow, I.E. and Cork, S.J. (1997). The effects of elevated $\mathrm{CO}_{2}$ atmospheres on the nutritional quality of Eucalyptus foliage and its interaction with soil nutrient and light availability. Oecologia., 109:59-68.

Rao, M., Manimanjari, D., Vanaja, M., Ramarao, C.A., Srinivas, K., Rao, V.U.M. and Venkateswarlu, B. (2012). Impact of elevated $\mathrm{CO}_{2}$ on tobacco caterpillar, Spodoptera litura on peanut. J. Insect Sci., 12(103): $1-10$.

Robinson, E.A., Geraldine, D.R. and Jonathan, A.N. (2012). Tansley Review. A meta-analytical review of the effects of elevated $\mathrm{CO}_{2}$ on plant arthropod interacting environmental and biological variables. New Phytol., 1-15.

Sharma, S. and Brar, S.T., (2018). Effects of elevated temperature and carbon dioxide on food consumption and growh of Spodoptera litura Fabricius on cauliflower. J. Agrometeorol., 20 (4): 305-310.

Wang, X., Lanzhu, Ji., Guiqing, W. and Yan, L. (2008). Potential effects of elevated $\mathrm{CO}_{2}$ on leaf-feeding forest insects. Frontier Biol. China, 3(1): 68-77.

Yadugiri. V.T. (2010). Climate change: the role of plant physiology. Curr. Sci., 99: 423-425. 